\title{
Numerical research of heated up to high temperatures particle influence on human skin
}

\author{
Nikolay V. Baranovskiy and Andrey S. Solodkin \\ National Research Tomsk Polytechnic University, Institute of Power Engineering, 634050, Tomsk, \\ Russian Federation
}

\begin{abstract}
Numerical research results of heated to high temperatures particle influence on human skin are presented. The problem is solved in two-dimensional statement in Cartesian system of coordinates. The typical range of influence parameters of heated particle is considered. Temperature distributiont in different moments of time are obtained.
\end{abstract}

\section{Introduction}

The problem of forest fires became especially actual last decade [1]. Catastrophic forest fire occur in the various states of our planet. It is enough to note events of 2009 to Australia or fires of 2010 in the Central Russia. There is a destruction of forest fund as a result of forest fire activity and atmosphere pollution by the products of forest fuel burning [2]. Besides, forest fires influence the person [3]. Probably formation of burns on human skin as a result of forest fire radiation action [4]. To this direction of researches the special attention is paid [5]. Questions of development of sheetings and materials for clothes of forest firemen are especially intensively investigated [6]. However, radiation is only one of mechanisms of heat transfer from of the burning centre to human skin [7]. Often enough from forest fire front are taken out heated up to high temperatures particles [8] which can contact to human skin. It is necessary to notice, that generally the problem of an estimation of heated particle influenced on the bared human skin is not solved. Such particles can from a different material, and also have the various form and structure. For example, there can be metal, carbonaceous, ceramic or polymeric particles. However in the present research we will be limited only to carbonaceous particles which correspond to the natural scenario, namely to forest fire. It is especially interesting to investigate influence of particles of the small size as they can be formed at forest fires in a considerable quantity.

Article purposes are development of two-dimensional mathematical model and numerical research of heat transfer processes at influence of heated up to high temperatures particle on not protected human skin.

\section{Physical and Mathematical Statement}

Usually a skin subdivide into two types - thick and thin, that is connected, mainly, with various thickness of epidermis. The thick skin covers palms and soles. For it presence thick epidermis on which external surface especially powerful layer of keratin settles down is characteristic. The skin has 
rather difficult structure having the features in various parts of a body. The skin consists of three layers: epidermis, derma and hypodermis [9].

Epidermis consists basically of dead cages which operate as a protective barrier against a moisture, ultra-violet radiation and heats [9]. Through epidermis pass sweat glands. The bottom layer of epidermis is basal, lays on basal membrane dividing epidermis and derma. Derma is the basic part of a skin. It much more thickly also comprises blood vessels, the nervous endings, sebaceous glands and hair roots. Epidermis and derma, together taken, have a thickness about 1-2 mm. Below these two layers the hypodermic fabric - fatty hypodermis which contains sweat glands and large blood vessels which give the chance to a skin to adapt to local heating or cooling, but only in certain limits [10].

At a thermal trauma initially there is a damage of cages that is expressed in infringement of their structure and functions. Barrier function of cellular and endocellular membranes is broken, and also ionic pumps are switched off. It, in turn, is accompanied by infringement of distribution of substances in a cage and between a cage and environment, disorganization of an endocellular metabolism and infringement of power supply system [11].

The burn trauma causes heavy metabolic frustration, breaks work of all links of oxygen delivery system, including decrease in warm emission, reduction of the maintenance of oxygen in arterial blood and infringement of its recycling [11].

At weak thermal influence of $1 \mathrm{~mm}$ depth will be damaged only epidermis. More intensive thermal flux can lead to defeat not only epidermis, but also derma. Radiation still more intensity will influence on hypodermis [9].

For understanding of the basic laws of heat transfer we will consider influence process of heated up to high temperatures particles on human skin taking into account following assumptions [12]:

1) Carbonaceous particles are considered. It corresponds to the scenario of natural fire danger. It is supposed, that such particles are formed as a result of thermal destruction of wood or forest fuels. Heated up to high temperatures particles are taken out from front of forest fire as a result of convective plume action.

2) The single-layered system of a human skin structure with effective thermophysical characteristics is considered.

3) It is supposed, that thermophysical characteristics of particle and skin do not depend on temperature.

4) Destruction of skin tissues under the influence of the raised temperatures is neglected.

5) Evaporation of a cellular moisture from skin tissues also is neglected.

6) Basic mechanism of heat transfer in skin is conduction.

7) Monolithic structure of a skin is considered.

The geometry of decision area is presented on fig. 1 .

Heat transfer process mathematically in considered system is described by system of the nonstationary differential equations in partial derivatives with corresponding boundary and initial conditions:

$$
\begin{aligned}
& \rho_{1} c_{1} \frac{\partial T_{1}}{\partial t}=\lambda_{1}\left(\frac{\partial^{2} T_{1}}{\partial x^{2}}+\frac{\partial^{2} T_{1}}{\partial z^{2}}\right), \quad \begin{array}{l}
0<x<L_{3} \\
0<z<H_{1}
\end{array} \\
& \left\{\rho_{2} c_{2} \frac{\partial T_{2}}{\partial t}=\lambda_{2}\left(\frac{\partial^{2} T_{2}}{\partial x^{2}}+\frac{\partial^{2} T_{2}}{\partial z^{2}}\right), \mid \begin{array}{l}
L_{1}<x<L_{2} \\
H_{1}<z<H_{2}
\end{array}\right. \\
& \rho_{3} c_{3} \frac{\partial T_{3}}{\partial t}=\lambda_{3}\left(\frac{\partial^{2} T_{3}}{\partial x^{2}}+\frac{\partial^{2} T_{3}}{\partial z^{2}}\right), \quad \begin{array}{c}
0<x<L_{3} \\
H_{2}<z<H_{3}
\end{array}
\end{aligned}
$$


TSOTR 2015

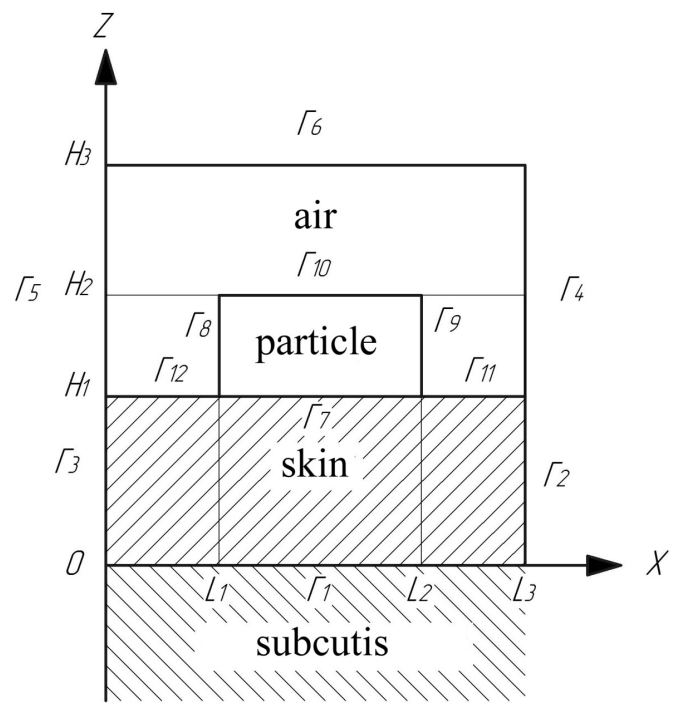

Figure 1. The scheme of decision area

Initial and boundary conditions accordingly:

$$
t=0: T_{i}=T_{i}^{0},
$$

$$
\begin{aligned}
& \Gamma_{1}: \lambda_{1} \frac{\partial T_{1}}{\partial z}=\alpha_{1}\left(T-T_{n c}\right), \alpha_{1}>0 \\
& \Gamma_{2}: \frac{\partial T}{\partial x}=0 ; \\
& \Gamma_{3}: \frac{\partial T}{\partial x}=0 \\
& \Gamma_{4}: \frac{\partial T}{\partial x}=0 ; \\
& \Gamma_{5}: \frac{\partial T}{\partial x}=0 ; \\
& \Gamma_{6}: T=T_{e} ; \\
& \Gamma_{7}: \lambda_{1} \frac{\partial T_{1}}{\partial z}=\lambda_{2} \frac{\partial T_{2}}{\partial z}, T_{1}(t, x, z)=T_{2}(t, x, z) ; \\
& \Gamma_{8}: \lambda_{2} \frac{\partial T_{2}}{\partial x}=\lambda_{3} \frac{\partial T_{3}}{\partial x}, T_{2}(t, x, z)=T_{3}(t, x, z) \\
& \Gamma_{9}: \lambda_{2} \frac{\partial T_{2}}{\partial x}=\lambda_{3} \frac{\partial T_{3}}{\partial x}, T_{2}(t, x, z)=T_{3}(t, x, z) \\
& \Gamma_{10}: \lambda_{2} \frac{\partial T_{2}}{\partial z}=\lambda_{3} \frac{\partial T_{3}}{\partial z}, T_{2}(t, x, z)=T_{3}(t, x, z)
\end{aligned}
$$




$$
\begin{gathered}
\Gamma_{11}: \lambda_{1} \frac{\partial T_{1}}{\partial z}=\lambda_{3} \frac{\partial T_{3}}{\partial z}, T_{1}(t, x, z)=T_{3}(t, x, z) ; \\
\Gamma_{12}: \lambda_{1} \frac{\partial T_{2}}{\partial z}=\lambda_{3} \frac{\partial T_{3}}{\partial z}, T_{1}(t, x, z)=T_{3}(t, x, z) ;
\end{gathered}
$$

Where $T_{i}, \rho_{i}, c_{i}, \lambda_{i}$ - temperature, density, thermal capacity and heat conductivity. Value of an index $i=1$ corresponds to heated particle, $i=2$ to an investigated site of a skin, $i=3$ to air. $t$ - time, $x, z$ spatial coordinates.

For the decision of the formulated system of the equations the finite difference method [13] is used. The two-dimensional equations of heat conductivity are solved by a locally-one-dimensional method [13]. Finite difference analogues of the differential equations are solved by a sweep method [13].

\section{Results and Discussion}

Numerical realization of mathematical model is provided in high level language Object Pascal. For computing experiments the computer of type IBM PC with two-core processor Intel Pentium $3 \mathrm{GHz}$ and RAM memory $8 \mathrm{~GB}$ was used. The two-dimensional mathematical model also one-dimensional allows to develop resource effective algorithm for program realization. Calculation of heat transfer process occurs in a mode advancing real time of development of process. It allows to say that the given mathematical model has prospects for use in modern medical information systems $[14,15]$.

In drawing 2 temperature distribution in system a particle-skin-air at the moment of time 1 and 3 seconds is presented 3 .

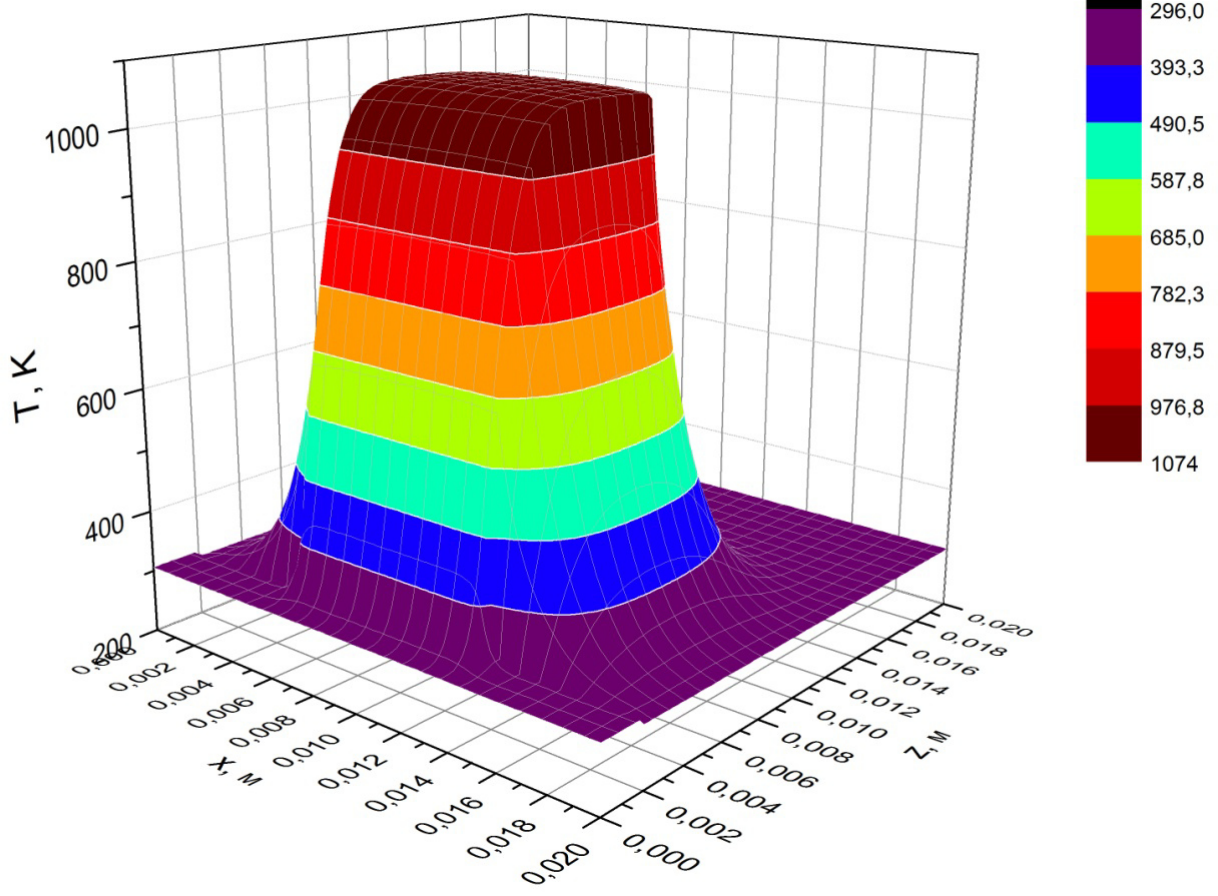

a) 


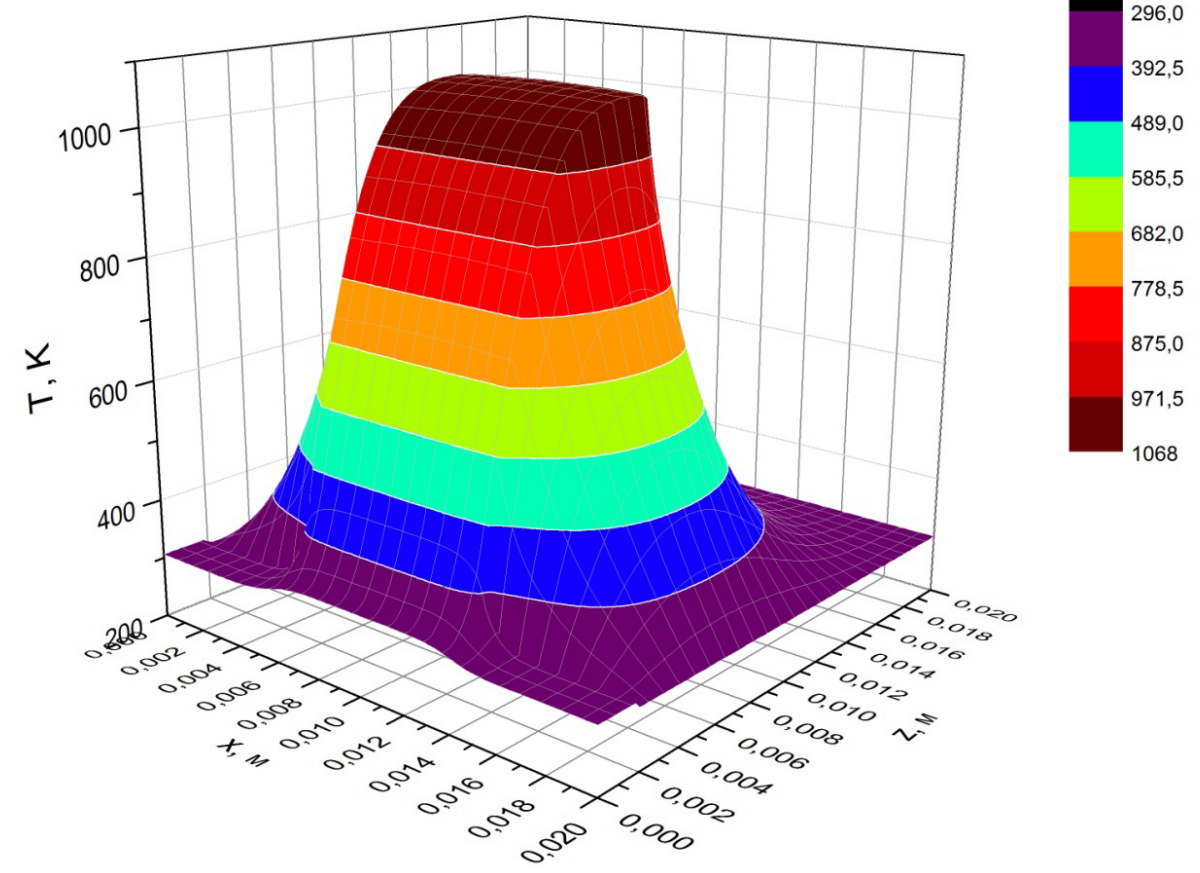

b)

Figure 2. Distribution of temperatures in system a skin-particle-air at the moment of time $t=1 \mathrm{~s}(\mathrm{a}), \mathrm{t}=3 \mathrm{~s}(\mathrm{~b})$

The analysis of the obtained distributions allows to ascertain, that eventually there is an intensive cooling of a particle for the account of heat output at interaction to environment and a skin hypodermic.

In the present work short-term influence of heated particle on human skin was accepted. This assumption corresponds to the scenario of behaviour of the person which has no traumas obtained as a result of a fire and is capable to exclude long influence of heated particles on skin. The analysis of pictures allows to draw a conclusion, that the particle intensively cools down as a result of environment and heat removal influence in skin layers of the person. Logical the conclusion serves that fact, that hotter particles represent the big danger to the person. Such particles have more stock of heat and are capable to cause more harm to tissues of human skin. The analysis of temperature distributions shows, that at any temperatures enough a hot particle appreciable influence is observed in the top millimetric layer of human skin. It is necessary to notice, that is necessary to study in more details research of heat transfer at rather not high and average temperatures of particles as in the course of the movement in the air environment they also cool down. In the future working out of certain scenarios of influence of heated particle on human skin and separation of so-called "hot", "moderately hot" and "cold" particles is possible.

\section{Conclusion}

Thus, the two-dimensional mathematical model of thermal influence of heated particle on human skin is developed. Heat transfer research of the basic laws is carried out at skin layer at influence of heated carbonaceous particle. As it has been told above, development of such model opens prospects to creation of new generation of medical information systems on the basis of determined mathematical 
models [16-19]. Development of the complex is deterministic-probabilistic approach with attraction of results of prognostic modelling of forest fire danger is possible.

\section{Acknowledgements}

Authors express gratitude for consultations to the professor Arhipov V.A and professor Zharova I.K. for valuable councils in training in Scientific research institute of applied mathematics and mechanics of Tomsk state university.

\section{References}

1. G.V. Kuznetsov, N.V. Baranovskiy, Prognoz vozniknoveniya lesnikh pozharov $i$ ikh ekologicheskikh posledstviy, (2009) (In Russian)

2. D.M.J.S. Bowman, J.H. Johnston, Ecohealth, 2, 76 (2005)

3. R.Sh. Enaleev, A.M. Zakirov, J.S. Chistov, E.Sh. Telyakov, Vestnik Kazanskogo tekhnologicheskogo universiteta, 15, 50 (2012) (In Russian)

4. E.N. Valendik, I.V. Kosov, Sibirskiy ecologicheskiy zhurnal, 4, 517 (2008) (In Russian)

5. A. Hummel, K. Lyons, Fire Technology, 50, 1285 (2014)

6. ASTM Standard D 4108-87, Standard test method for thermal protective performance of material for clothing by open flame method, American society for testing and materials (1994)

7. A.E. Pushkareva, Lazerniy selektivniy nagrev elementov kozhi. Diss. Cand. Tech. Sci. (2006) (In Russian)

8. V.V. Terebnev, N.S. Artemiev, A.V. Podgrushniy, Protivopozharnaya zashchita I tushenie pozharov. Kniga 5. Lesa, torphyaniki. Lesosklady (2007) (In Russian)

9. F. Xu, T.J. Lu, K.A. Seffen, Acta Mechanica Sinica, 24, 1 (2008)

10. B.A. Paramonov, Ya.O. Porembskiy, V.G. Yablonskiy, Ozhogi: Rukovodstvo dlya vrachey (2000) (In Russian)

11. M.V. Vildieva, Obosnovanie primeneniya meksidapta $v$ kompleksnom lechenii bolnikh $s$ termicheskoy travmoy, Diss. Cand. Med. Sci. (2009) (In Russian)

12. A.S. Solodkin, K.O. Ponomarev, Mathematical Simulation of Heat Impact of Heated Up to High Temperatures Particle on Human Skin: Simple One-Dimensional Statement // MATEC Web of Conference. 2014. 19. Paper 01034. P. 1 - 6.

13. A.A. Samarskiy, P.N. Vabishchevich, Additivnie skhemy dlya zadach matematicheskoy fiziki (2001) (In Russian)

14. S. Petter, A. Fruhling, International journal of medical informatics, 80, 480 (2011)

15. N. Bricon-Souf, C. Verdier, A. Flory, M.C. Jaulent, IRBM, 34, 9 (2013)

16. A.M. Grishin, N.V. Baranovskij, Journal of Engineering Physics and Thermophysics, 76, 166 (2003)

17. G.V. Kuznetsov, N.V. Baranovskiy, EPJ Web of Conferences, 76 (01028), 1 (2014)

18. G.V. Kuznetsov, N.V. Baranovskiy, Proceedings of SPIE, 8890, paper 889011 (2013) doi:10.1117/12.2033929

19. D.V. Korobkina, N.V. Baranovskiy, Cloud of Science, 1, 292 (2014) (In Russian) 